\title{
Article \\ Squamous Cell Carcinoma of the Vulva: A Survival and Epidemiologic Study with Focus on Surgery and Radiotherapy
}

\author{
Matteo Scampa (), Daniel F. Kalbermatten and Carlo M. Oranges *
}

check for updates

Citation: Scampa, M.; Kalbermatten, D.F.; Oranges, C.M. Squamous Cell Carcinoma of the Vulva: A Survival and Epidemiologic Study with Focus on Surgery and Radiotherapy. J. Clin. Med. 2022, 11, 1025. https://doi.org/ $10.3390 / j \mathrm{~cm} 11041025$

Academic Editor: Jacek Malejczyk

Received: 31 December 2021

Accepted: 14 February 2022

Published: 16 February 2022

Publisher's Note: MDPI stays neutral with regard to jurisdictional claims in published maps and institutional affiliations.

Copyright: (C) 2022 by the authors. Licensee MDPI, Basel, Switzerland. This article is an open access article distributed under the terms and conditions of the Creative Commons Attribution (CC BY) license (https:// creativecommons.org/licenses/by/ $4.0 /)$.

\author{
Department of Plastic, Reconstructive and Aesthetic Surgery, Geneva University Hospitals, University of Geneva \\ 1205 Geneva, Switzerland; matteo.scampa@hcuge.ch (M.S.); daniel.kalbermatten@hcuge.ch (D.F.K.) \\ * Correspondence: carlo.oranges@hcuge.ch; Tel.: +41-(0)22-372-79-97
}

\begin{abstract}
Vulvar squamous cell carcinoma (SCC) is the most frequent vulvar neoplasia. While the primary role of surgery is widely accepted, large population studies are needed to compare survival between diverse treatment modalities and to identify independent prognostic factors to help council patients and guide oncological treatment. The U.S. National Cancer Index, Surveillance, Epidemiology and End Results (SEER) program data between 2000 and 2018 was screened for all squamous cell carcinoma affecting the vulva. Raw data was processed with IBM SPSS. Demographic, clinical-pathological and treatment data were studied. Overall survival (OS) was calculated using the Kaplan-Meier method and subgroups were compared using the log rank test. A multivariate cox regression was conducted to identify independent prognostic factors. A total of 11,360 patients were identified with a median age of 65. Median overall survival was 101 months. Surgery as a primary treatment is the therapeutic sequence associated with the best overall survival. Multivariate coxregression did not meet proportional hazard assumption. Age, pathological grade, stage at diagnosis, treatment sequence and the use of chemotherapy were identified as independent prognostic factor. Surgery alone is the treatment sequence offering the best overall survival. Surgery should be offered to all eligible patients.
\end{abstract}

Keywords: vulva; squamous cell carcinoma; survival; epidemiology; SEER

\section{Introduction}

Squamous cell carcinoma (SCC) can affect a large number of organs covered by squamous epithelial lining such as the vulva skin and the vagina [1]. Vulvar carcinoma is one of the less common gynaecological neoplasia with incidence as low as 2.6 per 100,000 person per year [2,3]. SCC represents the majority of vulvar cancer. Vulvar SCC can have different clinical presentations such as ulcerated plates or wart-like lesions with different colorations reported [4]. The carcinogenesis can occur with two different pathways. High-risk human papillomavirus (HPV) infection, despite its known role in cervical cancer, can also trigger vulvar SCC. Individuals tend to be young patients whereas HPV-independent SCC usually occurs in older individuals with chronic inflammatory background such as lichen sclerosis [5]. Precursor lesions have been identified as squamous intraepithelial lesion (SIL), typically associated with papillomavirus infection, and differentiated vulvar intraepithelial neoplasia (dVIN), usually associated with chronic inflammation. The two precursors present different characteristics and behaviour [6,7].

Due to invasive behaviour, SCC requires a multidisciplinary approach to limit disease burden, recurrence and mortality. In current guidelines, surgery maintains a main role in local and regional control. Use of adjunctive treatments such as radiotherapy is frequent [8]. Radical vulvectomy and radical local excision can lead to extensive soft tissues defects, local function impairment (urinary or faecal incontinence) and sexual disfunctions [9]. Plastic surgeons maintain an important role by providing local reconstruction allowing restoration of function and cosmetic improvement. Early detection allows to treat the 
neoplasia at a localized stage with less invasive surgery. Large population studies that focus on epidemiology and survival are needed to improve surgical care and identify prognostic factors. The Surveillance, Epidemiology and End Results (SEER) program of the National Cancer Institute (NCI) is an incidence and survival database that covers up to $35 \%$ of the USA and allows large population study for low incidence tumours [10].

Studies assessing the SEER database for data on vulvar carcinoma were conducted, but to our knowledge none focused specifically on SCC and its association between demographics, treatment and overall survival [11-14].

The aim of our study is to offer recent epidemiologic and survival data over the vulvar SCC by focusing on surgery and radiation therapy to improve surgical care and help guide patient counselling.

\section{Materials and Methods}

Patient selection: The NCI SEER database including data between 2000 and 2018 through 18 registries was screened for all squamous cell carcinoma using ICD-O3 histopathological codes 8070 to 8085 . Primary topographic site was selected using ICD codes for Labium Majus (C51.0), Labium Minus (C51.1), Clitoris (C51.2), Overlapping lesion of vulva (C51.8) and Vulva, NOS (Not Otherwise Specified) (C51.9).

Analysis: Raw data were extracted using the case listing function of the survival session of the Surveillance Research Program, National Cancer Institute SEER*Stat software (seer.cancer.gov/seerstat, accessed on 30 December 2021) version 8.3.9 and processed through IBM SPSS v.27 (IBM, Armonk, NY, USA). Epidemiologic and clinical-pathological characteristics of patients were described. Overall survival (OS) was calculated using the Kaplan-Meier method and was defined as the time from diagnosis to death regardless of the cause. Log-rank test was used to compare OS between subgroups. Multi-variate Cox regression was used to identify independent prognostic factors. To validate results, a proportional hazards $(\mathrm{PH})$ assumption test was conducted using Schoenfeld's residuals. A $p$-value of $<0.05$ was considered statistically significant. Unknown or missing data were not included in statistical analysis.

Variable selection: SEER variables were used when available (age, race, marital status, stage at diagnosis, type of surgery, radiotherapy and chemotherapy), but some were created using the merging function of the SEER* ${ }^{*}$ tat software that allows to combine different variables (pathological grade, treatment sequence). For comparing OS between age groups, 3 categories were created: $<65$ years old (y.o.); 65-79 y.o.; $\geq 80$ y.o. Age subdivision in three categories was performed by randomly assuming patients younger than 65 were expected to be fit and active with a better prognosis, whereas patient of/over 80 years old had more comorbidities and a lower OS was expected. Stage at diagnosis was based on the SEER summary stage where localized disease is defined as an invasive carcinoma with or without stromal invasion confined to musculature, submucosa and vulva including the skin. Regional disease is characterized by direct extension to adjacent perineal structures such as the anus, peri-anal skin, bladder, distal third urethra, rectum and vagina or/and regional lymph nodes involvement. Distant disease includes further extension such as bladder or rectal mucosa, rest of urethra (proximal 2/3), pelvic bone, perineal body and/or distant lymph nodes. Further details are available on the SEER program website [15]. Since 2018, the pathological grade of tumour reported in the SEER database uses a 3-category classification, meaning Grade IV (anaplastic tumours) were combined with Grade III (poorly differentiated). To ease results interpretation, we converted all data from before 2018 in this 3-stage system. When assessing histologic sub-types, we considered for analysis only sub-types that represented more than $1 \%$ of the study population because most of the 13 subtypes included less than 100 patients. Treatment sequence variable was created by merging the surgery and radiation variables. It included 4 subgroups, where surgery included all kind of surgery and even unknown surgery if documented as surgery unknown. Radiotherapy included all kind of radiation therapy without distinction between neo-adjuvant and adjuvant. 


\section{Results}

A cohort of 11,360 patients was identified (Table 1). Median age at diagnosis was 65 years with a range from 17 to 99 years (Figure 1). Between 2000 and 2018, a small increase in cases diagnosed by year has been observed through the years (Figure 2). When assessing demographic and clinical-pathological characteristics, we noted that most of the patient were white married women with a localized disease. Vulva, not otherwise specified (NOS) was reported as the most frequent primary site.

Table 1. Demographic and clinical-pathological features of vulvar squamous cell carcinoma.

\begin{tabular}{|c|c|}
\hline & $\mathbf{N}(\%)$ \\
\hline \multicolumn{2}{|l|}{ Age } \\
\hline Median & 65 (range 17-99) \\
\hline$<65$ years old & $5440(57.9)$ \\
\hline 65 to 79 years old & $3409(30)$ \\
\hline$\geq 80$ years old & $2511(22.1)$ \\
\hline \multicolumn{2}{|l|}{ Race } \\
\hline White & $9895(87.1)$ \\
\hline Black & $1045(9.2)$ \\
\hline American Indian/Alaska Native & $69(0.6)$ \\
\hline Asian or Pacific Islander & $255(2.2)$ \\
\hline Unknown & $96(0.8)$ \\
\hline \multicolumn{2}{|l|}{ Marital status } \\
\hline Married & $4179(36.8)$ \\
\hline Not Married & $3587(31.6)$ \\
\hline Widowed & $2745(24.2)$ \\
\hline Unknown & $849(7.5)$ \\
\hline \multicolumn{2}{|l|}{ Primary site } \\
\hline C51.0 Labium majus & $965(8.5)$ \\
\hline C51.1 Labium minus & $536(4.7)$ \\
\hline C51.2 Clitoris & $211(1.9)$ \\
\hline C51.8 Overlapping lesion of vulva & $521(4.6)$ \\
\hline C51.9 Vulva, NOS * & $9127(80.3)$ \\
\hline \multicolumn{2}{|l|}{ Histologic subtypes } \\
\hline 8070/3 Squamous cell carcinoma, NOS * & $7740(68.1)$ \\
\hline $\begin{array}{l}\text { 8071/3 Squamous cell carcinoma, keratinizing, } \\
\text { NOS * }\end{array}$ & $2889(25.4)$ \\
\hline $\begin{array}{c}\text { 8072/3 Squamous cell carcinoma, large cell, } \\
\text { non-keratinizing, NOS * }\end{array}$ & $248(2.2)$ \\
\hline $\begin{array}{c}\text { 8076/3 Squamous cell carcinoma, } \\
\text { micro-invasive }\end{array}$ & $266(2.3)$ \\
\hline 8083/3 Basaloid squamous cell carcinoma & $173(1.5)$ \\
\hline \multicolumn{2}{|l|}{ Pathologic grade } \\
\hline G1: Well differentiated & $2900(25.5)$ \\
\hline G2: Moderately differentiated & $4317(38)$ \\
\hline G3: Poorly differentiated/Anaplastic & $1761(15.5)$ \\
\hline Unknown & $2382(21)$ \\
\hline \multicolumn{2}{|l|}{ Stage at diagnosis } \\
\hline Localized & $6425(56.6)$ \\
\hline Regional & $3897(34.3)$ \\
\hline Distant & $664(5.8)$ \\
\hline Unknown & $374(3.3)$ \\
\hline No surgery & $2122(18.7)$ \\
\hline
\end{tabular}


Table 1. Cont.

\begin{tabular}{cc}
\hline & $\mathbf{N} \mathbf{( \% )}$ \\
\hline Surgery & $9204(80.9)$ \\
Local destruction & $13(0.1)$ \\
Local excision & $1591(14)$ \\
Simple/partial surgical removal of primary site & $3831(33.7)$ \\
Total surgical removal of primary site & $1405(12.4)$ \\
Debulking surgery & $25(0.2)$ \\
En bloc resection & $2277(20)$ \\
Surgery, NOS * & $62(0.5)$ \\
\hline Unknown & $34(0.3)$ \\
\hline Radiotherapy & \\
Yes & $3473(30.6)$ \\
No/unknown & $7886(69.4)$ \\
\hline Treatment & $745(6.6)$ \\
No surgery and no radiotherapy & $1353(11.9)$ \\
Radiotherapy without surgery & $7028(61.9)$ \\
Surgery without radiotherapy & $2115(18.6)$ \\
Surgery with radiotherapy & \\
Chemotherapy & $2079(18.3)$ \\
Yes & $9281(81.7)$ \\
\hline No/unknown &
\end{tabular}

* NOS: Not Otherwise Specified.

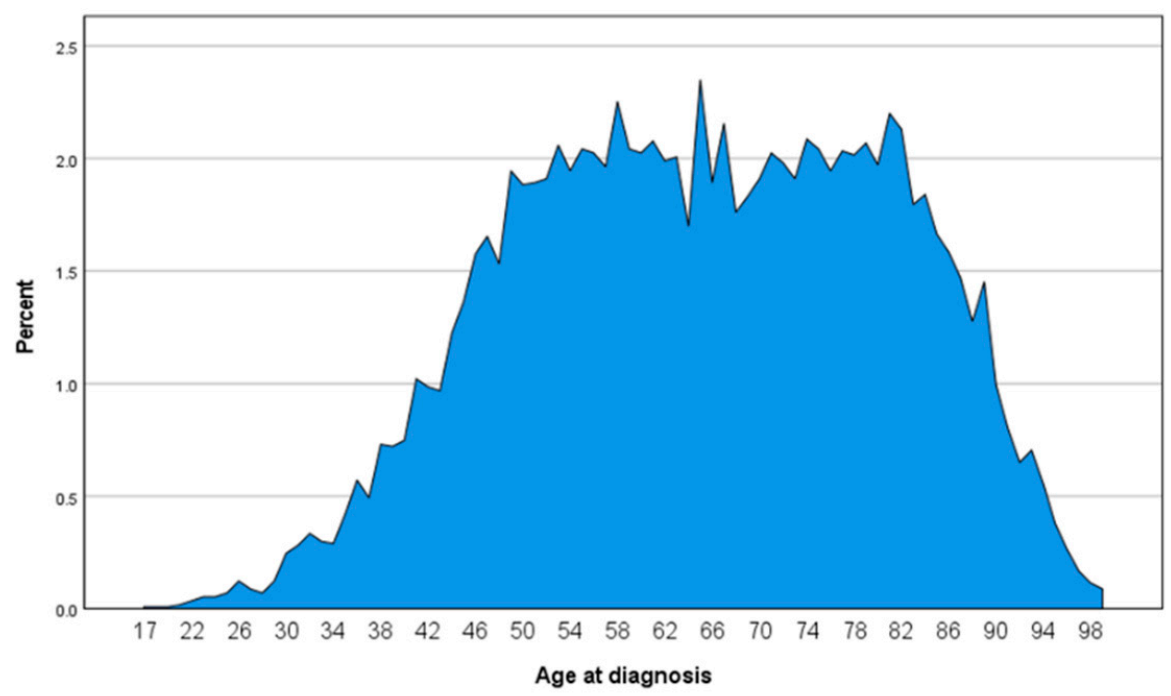

Figure 1. Diagnosis age distribution of vulvar squamous cell carcinoma.

Thirteen different histologic subtypes were described, but $68.1 \%$ were categorized under squamous cell carcinoma, NOS. The mean initial tumour size was $33.5 \mathrm{~mm}(\sigma=37.6$; median 27). Most patients had a moderately differentiated pathological grade (G2). Surgery was performed in $80.9 \%$, with simple/partial surgical removal of primary site being the most reported category $(33.7 \%)$. A minority of patients received radiation therapy $(30.6 \%)$ and the use of chemotherapy was rare $(18.3 \%)$. A total of 3247 patients $(93.5 \%)$ were treated with beam radiation, 121 (3.5\%) with a combination of beam radiation with implants or isotopes, 27 patients $(<1 \%)$ with radioactive implants or radioisotopes. The majority of patients received radiotherapy after surgery (2035 patients), 237 patients received radiotherapy prior to surgery and 27 received radiation therapy before and after surgery. For patients that did not benefit from surgery the main reason reported was "not recommended". 


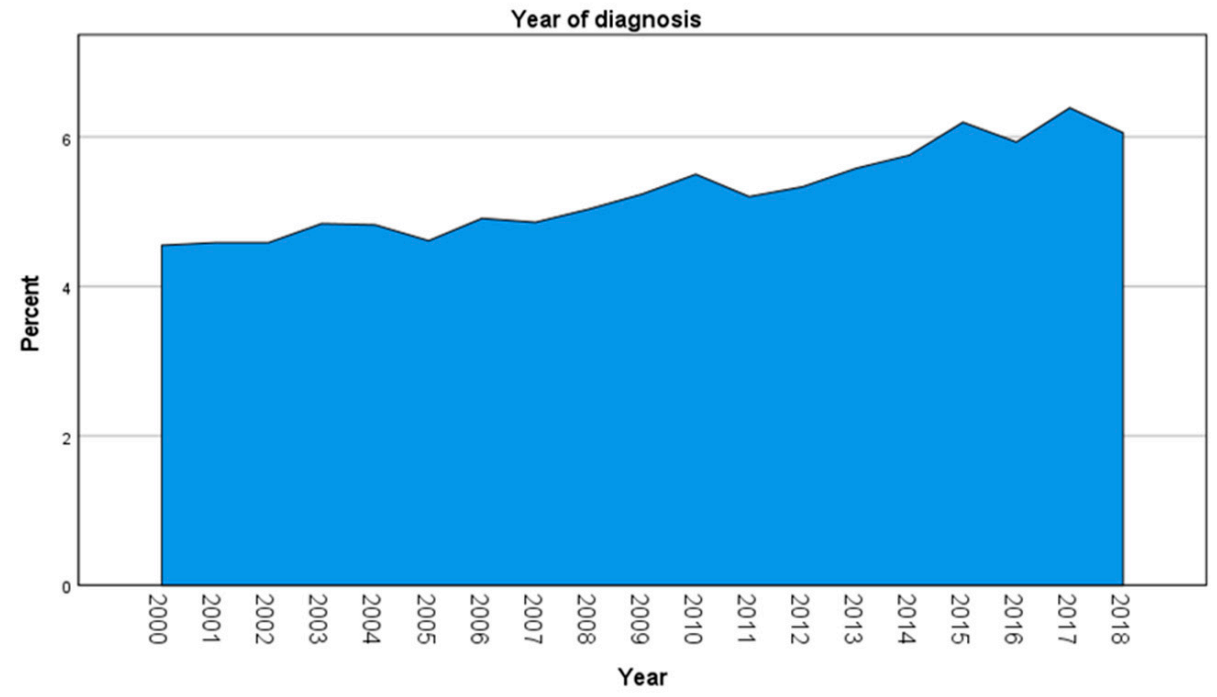

Figure 2. Distribution of vulvar squamous cell carcinoma cases through the years.

Median OS was 101 months (m) (95\% CI \{96.4-105.6\}). Five-year OS was 60.6\%; 10 years OS was $45.7 \%$; and 15 years OS was $33.1 \%$.

When assessing OS between three categories of age we found statistical difference $(p<0.05)$ between each group (Figure 3$)$. Between all primary site, overlapping lesion of the vulva was found to have the lowest OS compared to other sites $(p<0.05)$. We also found statistical difference between Vulva, NOS and labium minus. Other sites, however, did not differ significantly in terms of OS (Figure 4). According to histological subtype, squamous cell carcinoma, keratinizing, NOS (ICD-O3 8071/3) was found to have the lowest OS $(p<0.05)$. Squamous cell carcinoma, micro-invasive (ICD-O3 8076/3), followed by basaloid squamous cell carcinoma (ICD-O3 8083/3) were found to have significantly better OS than other histological subtypes $(p<0.05)$. However, no statistical difference was found between squamous cell carcinoma, NOS (ICD-O3 8070/3) and squamous cell carcinoma, large cell, non-keratinizing, NOS (ICD-O3 8072/3).
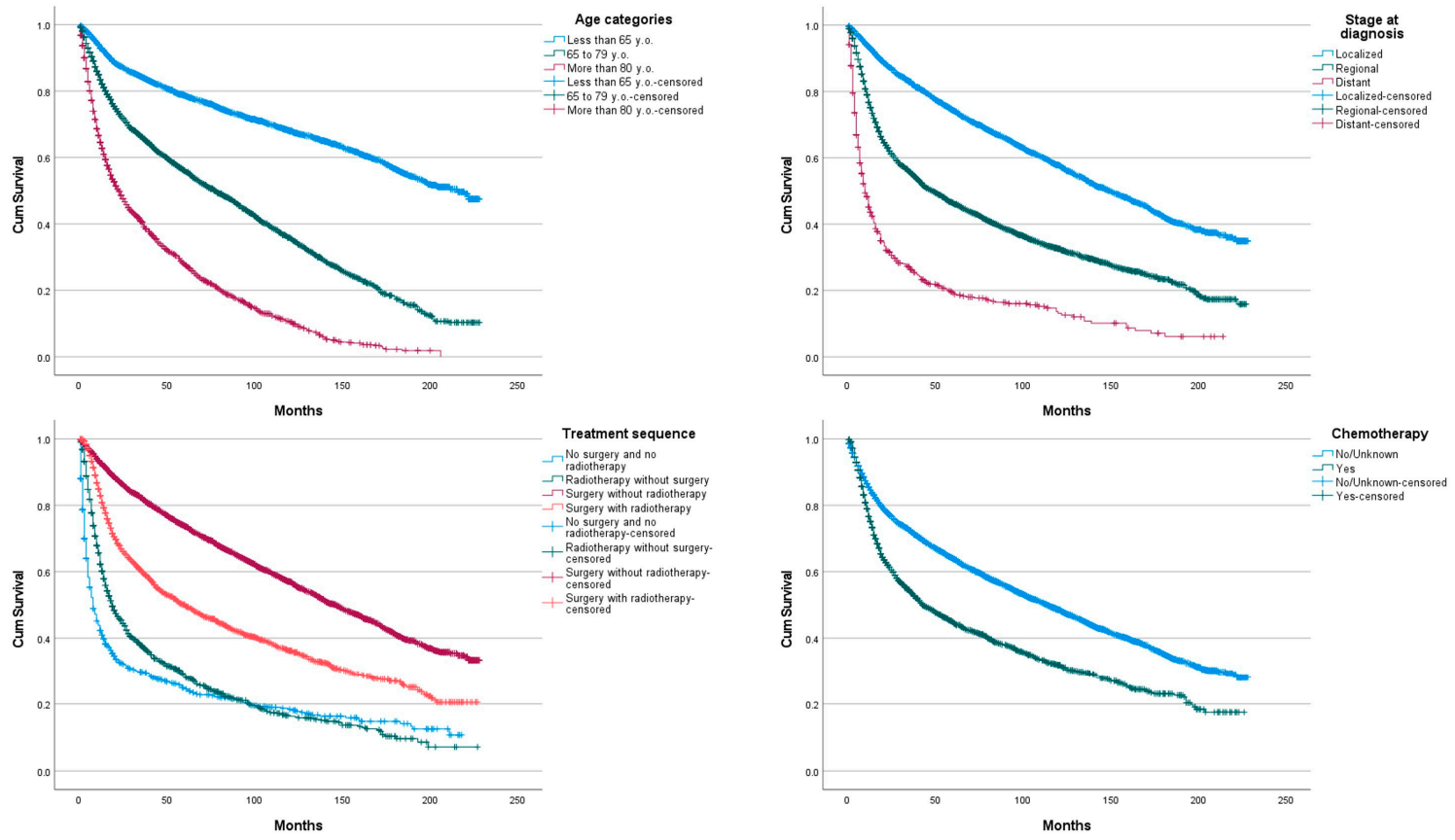

Figure 3. Vulvar squamous cell carcinoma overall survival according to age, stage at diagnosis, treatment sequence and use of chemotherapy. 

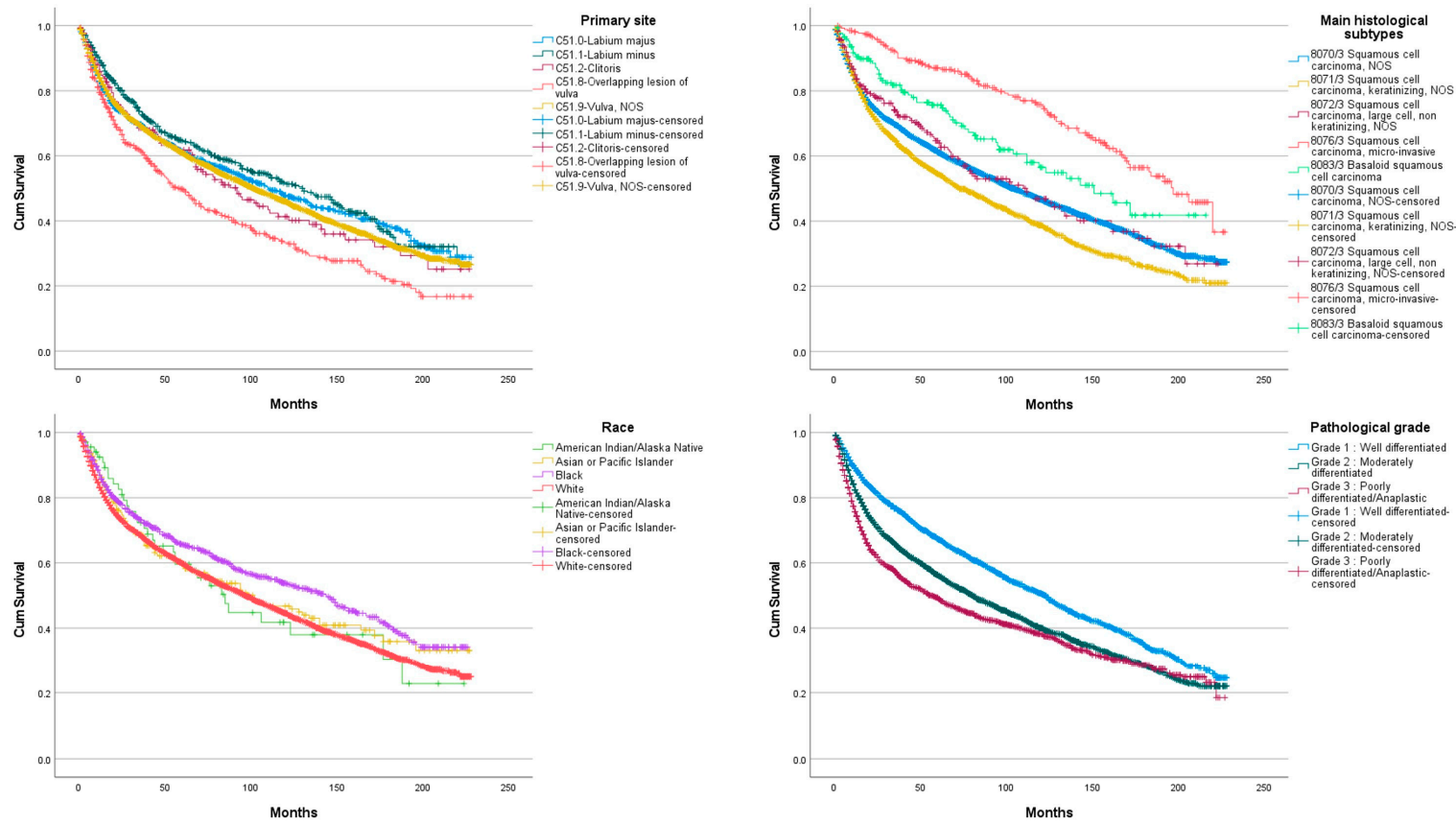

Figure 4. Vulvar squamous cell carcinoma overall survival according to primary site, histological subtype, race and pathological grade.

When assessing OS between races, we found a statistical difference between white and black populations with the later having a better OS. OS significantly lowered with pathological grade increasing $(p<0.05)$. Regional and distant invasion at diagnosis is associated with lower OS $(p<0.05)$. Surgery without radiotherapy was the treatment sequence associated with the better OS, followed by surgery with radiotherapy, radiotherapy without surgery and no surgery and no radiotherapy. OS differences between each sequence was statistically significant $(p<0.05)$. The use of chemotherapy was associated with low OS ( $p<$ 0.05).

Cox regression included 8606 cases. A total of 2754 cases were dropped due to missing data, corresponding to $24.2 \%$ of the total population. With the multivariate cox-regression we identified age, some of the main histological subtypes, pathological grade, some of the races, stage at diagnosis, treatment sequence and the use of chemotherapy as independent prognostic factors of improved survival (Table 2). Surgery without radiotherapy presented a significant hazard ratio of $0.227(95 \% \mathrm{CI}\{0.200-0.258\})$ compared to no surgery and no radiotherapy. However, age at diagnosis, main histological subtype, pathological grade, treatment sequence and chemotherapy did not meet the proportional hazard assumption necessary to validate the Cox regression model. Caution should be employed when interpreting prognostic factors.

Table 2. Multivariate Cox-regression of vulvar squamous cell carcinoma.

\begin{tabular}{cccccc}
\hline & B & Sig. & Exp(B) & $\begin{array}{c}\text { 95\% CI for Exp(B) } \\
\text { Low/Up }\end{array}$ \\
\hline Age: 3 subgroups & & & & & \\
Less than 65 y.o. & & 0.000 & & \\
65 to 79 y.o. & 0.936 & 0.000 & 2.550 & $2.360-2.756$ \\
More than 80 y.o. & 1.647 & 0.000 & 5.193 & $4.790-5.631$ \\
\hline
\end{tabular}


Table 2. Cont.

\begin{tabular}{|c|c|c|c|c|}
\hline & B & Sig. & $\operatorname{Exp}(B)$ & $\begin{array}{c}95 \% \text { CI for } \operatorname{Exp}(B) \\
\text { Low/Up }\end{array}$ \\
\hline \multicolumn{5}{|l|}{ Primary site } \\
\hline Labium majus & & 0.472 & & \\
\hline Labium minus & 0.066 & 0.446 & 1.068 & $0.902-1.264$ \\
\hline Clitoris & 0.139 & 0.235 & 1.149 & $0.914-1.444$ \\
\hline Overlapping lesion of vulva & 0.132 & 0.102 & 1.141 & $0.974-1.337$ \\
\hline Vulva, NOS & 0.084 & 0.123 & 1.087 & $0.978-1.209$ \\
\hline \multicolumn{5}{|l|}{ Main histological subtype } \\
\hline $8070 / 3$ Squamous cell carcinoma, NOS & & 0.000 & & \\
\hline 8071/3 Squamous cell carcinoma, keratinizing, NOS & 0.123 & 0.000 & 1.131 & $1.057-1.211$ \\
\hline 8072/3 Squamous cell carcinoma, large cell, non-keratinizing, NOS & -0.325 & 0.003 & 0.722 & $0.583-0.895$ \\
\hline 8076/3 Squamous cell carcinoma, micro-invasive & -0.246 & 0.189 & 0.782 & $0.541-1.129$ \\
\hline 8083/3 Basaloid squamous cell carcinoma & -0.273 & 0.075 & 0.761 & $0.564-1.028$ \\
\hline \multicolumn{5}{|l|}{ Pathological grade } \\
\hline Grade 1: Well differentiated & & 0.000 & & \\
\hline Grade 2: Moderately differentiated & 0.153 & 0.000 & 1.165 & $1.083-1.253$ \\
\hline Grade 3: Poorly differentiated/Anaplastic & 0.285 & 0.000 & 1.330 & $1.215-1.456$ \\
\hline \multicolumn{5}{|l|}{ Stage at diagnosis } \\
\hline Localized & & 0.000 & & \\
\hline Regional & 0.524 & 0.000 & 1.689 & $1.568-1.820$ \\
\hline Distant & 1.196 & 0.000 & 3.308 & $2.913-3.755$ \\
\hline \multicolumn{5}{|l|}{ Race } \\
\hline American Indian/Alaska Native & & 0.000 & & \\
\hline Asian or Pacific Islander & -0.671 & 0.001 & 0.511 & $0.339-0.772$ \\
\hline Black & -0.423 & 0.028 & 0.655 & $0.450-0.955$ \\
\hline White & -0.274 & 0.136 & 0.760 & $0.530-1.090$ \\
\hline \multicolumn{5}{|l|}{ Treatment sequence } \\
\hline No surgery and no radiotherapy & & 0.000 & & \\
\hline Radiotherapy without surgery & -0.577 & 0.000 & 0.562 & $0.484-0.652$ \\
\hline Surgery without radiotherapy & -1.482 & 0.000 & 0.227 & $0.200-0.258$ \\
\hline Surgery with radiotherapy & -1.162 & 0.000 & 0.313 & $0.273-0.359$ \\
\hline \multicolumn{5}{|l|}{ Chemotherapy } \\
\hline \multicolumn{5}{|l|}{ No/Unknown } \\
\hline Yes & -0.190 & 0.000 & 0.827 & $0.750-0.910$ \\
\hline
\end{tabular}

\section{Discussion}

Our study identified more than 11,000 vulvar SCC cases and is to our knowledge the biggest survival study population [11,16-20]. We found that vulvar SCC affects a majority of white women with disease mostly diagnosed at a localized stage. Those results affirm current knowledge [16-20]. Pathological grade 2 (moderately differentiated) is also reported as the most frequent by several studies $[16,20]$. Age at diagnosis seems to be younger in our population compared to other studies $[16,17,19,20]$. Elderly patients have the lowest survival of the three categories.

In our study more than $60 \%$ of our population benefit from surgery as the sole treatment modality. Results confirms current literature where surgery alone is the most frequently reported treatment sequence followed by its association with radiotherapy and finally radiotherapy alone $[16,19,20]$. Rottman et al. reported partial vulvectomy, followed by wide excision as the most frequent procedures [20]. Comparison with our results is limited because of different designations in the SEER database, but the trend is similar with simple/partial surgical removal of primary site, followed by "en bloc" resection being the most frequent procedures. Results stay in line with current recommendations. The National Comprehensive Cancer Network recommends wide local excision for localized disease with less than $1 \mathrm{~mm}$ invasion and radical local excision or modified radical vulvectomy with 
lymph node assessment (sentinel lymph node or nodal dissection) for localized disease with more than $1 \mathrm{~mm}$ invasion. For advanced diseases (locally advanced and regional), lymph node control maintains an important role and may require adjuvant radiotherapy and/or chemotherapy [14]. Distant disease requires multimodal palliative care [8].

Interestingly in our population 5-year OS was better than the one reported by Hellman in Sweden and Rottmann in Germany (59\% and 55\%, respectively), this could be correlated to the older median age reported by both studies because age has been identified as an independent prognostic factor in our study $[16,20]$. Surgery without radiotherapy has been identified as the treatment offering the best OS in the study population. This result seems to be especially true for localized disease (most of the study patients) where it has been recommended as standalone treatment. However, its role as a standalone treatment in more advanced disease is questionable with regional disease OS being lower. Surgery associated with radiotherapy is currently recommended for diseases with nodal involvement. Gill suggested that the concomitant use of adjuvant chemotherapy to adjuvant radiotherapy in patient with nodal involvement improved overall survival [21].

Radiotherapy alone, however, did not offer drastic improvement in survival compared to no treatment, except a small improvement in the first year compared to the later. Stecklein suggested that radiotherapy as a sole treatment might have a role in regional control for locally advanced tumours deemed unresectable [22].

Interestingly in our study we found that the overall survival of patient that benefited from chemotherapy was statistically lower from those who did not benefit from it. This observation can be explained by an indication bias: chemotherapy is used mainly in patients with advanced disease, with a lower survival. Rao et al, suggested that chemotherapy associated with radiotherapy was superior to radiotherapy alone in patients that did not benefit from surgery [23]. Reade et al, suggested in their review that while some studies suggest a positive impact of chemoradiation, the use of chemotherapy as a sole treatment remains questionable in the absence of new studies due to limited survival and high treatment toxicity [24]. Despite a non-valid Cox regression model due to $\mathrm{PH}$ assumption not being met, our results showed similar results to the VULCAN study who also identified chemotherapy as an independent prognostic factor of improved survival [25].

The role of adjuvant and neo-adjuvant therapies is believed to be mainly relevant in regional or distant disease. However, as Mazzotta et al. suggested in their review, the level of evidence remains low and further research must be conducted to assess their real impact on survival and recurrence and to define the optimal tailored treatment strategy [26].

Survival analysis according to treatment sequences should be interpreted cautiously as indication bias can be frequent, as seen for the use of chemotherapy in this article. It is one of the main limitations of the SEER database, which does not report the scope of treatment. The aim of lymph node procedures was not specified (diagnostic vs. curative) and their analysis was not conducted to avoid potential bias. Furthermore, some variables such as the positive lymph node count and their location were incomplete and not included in our analysis.

Another limitation of our study was the incapacity to integrate HPV status in our survival data because it was not reported in SEER. HPV positive SCC seem to have a better overall survival compared to HPV-independent SCC and non-surgical treatment might have a different impact [6,27-29]. Further studies assessing survival according to different treatment sequences in HPV positive and negative patients are required.

\section{Conclusions}

Vulvar SCC is a rare disease affecting women around their sixties and mainly diagnosed at a localized stage. Outcome is mainly determined by the age of the patient, pathological grade, stage at diagnosis and the choice of treatment. We found that surgery maintains a primordial role in primary disease control and offer the best overall survival compared to other treatment sequences. Surgery should be offered to all eligible patients. 
Further studies should be conducted to assess survival and recurrence outcomes between different treatment modalities and different stage of disease.

Author Contributions: M.S. extracted the data and conducted statistical analysis. M.S. and C.M.O. wrote the manuscript with the help of D.F.K. who offered proofreading and expertise. C.M.O. ensured supervision and coordination between authors. All authors have read and agreed to the published version of the manuscript.

Funding: This research received no external funding.

Institutional Review Board Statement: Not applicable.

Informed Consent Statement: Not applicable.

Data Availability Statement: Raw data available on the SEER program https:/ / seer.cancer.gov/ (accessed on 30 December 2021).

Conflicts of Interest: The authors declare no conflict of interest.

\section{References}

1. Yan, W.; Wistuba, I.I.; Emmert-Buck, M.R.; Erickson, H.S. Squamous Cell Carcinoma-Similarities and Differences among Anatomical Sites. Am. J. Cancer Res. 2011, 1, 275. [PubMed]

2. Cancer of the Vulva-Cancer Stat Facts. Available online: https://seer.cancer.gov/statfacts/html/vulva.html (accessed on 4 September 2021).

3. Siegel, R.L.; Miller, K.D.; Fuchs, H.E.; Jemal, A. Cancer Statistics, 2021. CA. Cancer J. Clin. 2021, 71, 7-33. [CrossRef] [PubMed]

4. Tan, A.; Bieber, A.K.; Stein, J.A.; Pomeranz, M.K. Diagnosis and Management of Vulvar Cancer: A Review. J. Am. Acad. Dermatol 2019, 81, 1387-1396. [CrossRef]

5. Singh, N.; Gilks, C.B. Vulval Squamous Cell Carcinoma and Its Precursors. Histopathology 2020, 76, 128-138. [CrossRef]

6. Hinten, F.; Molijn, A.; Eckhardt, L.; Massuger, L.F.A.G.; Quint, W.; Bult, P.; Bulten, J.; Melchers, W.J.G.; de Hullu, J.A. Vulvar Cancer: Two Pathways with Different Localization and Prognosis. Gynecol. Oncol. 2018, 149, 310-317. [CrossRef] [PubMed]

7. Bornstein, J.; Bogliatto, F.; Haefner, H.K.; Stockdale, C.K.; Preti, M.; Bohl, T.G.; Reutter, J.; ISSVD Terminology Committee. The 2015 International Society for the Study of Vulvovaginal Disease (ISSVD) Terminology of Vulvar Squamous Intraepithelial Lesions. J. Low Genit. Tract Dis. 2016, 20, 11-14. [CrossRef] [PubMed]

8. Koh, W.-J.; Greer, B.E.; Abu-Rustum, N.R.; Campos, S.M.; Cho, K.R.; Chon, H.S.; Chu, C.; Cohn, D.; Crispens, M.A.; Dizon, D.S.; et al. Vulvar Cancer, Version 1.2017, NCCN Clinical Practice Guidelines in Oncology. J. Natl. Compr. Canc. Netw. 2017, 15, 92-120. [CrossRef]

9. Aerts, L.; Enzlin, P.; Vergote, I.; Verhaeghe, J.; Poppe, W.; Amant, F. Sexual, Psychological, and Relational Functioning in Women after Surgical Treatment for Vulvar Malignancy: A Literature Review. J. Sex. Med. 2012, 9, 361-371. [CrossRef]

10. About the SEER Program. Available online: https:/ / seer.cancer.gov/about/overview.html (accessed on 10 April 2021).

11. Stroup, A.M.; Harlan, L.C.; Trimble, E.L. Demographic, Clinical, and Treatment Trends among Women Diagnosed with Vulvar Cancer in the United States. Gynecol. Oncol. 2008, 108, 577-583. [CrossRef]

12. Alhatem, A.; Lambert, W.C.; Karanfilian, K.; Behbahani, S.; Heller, D. Impact of Partnership Status on Clinical Outcomes of Patients with Vulvar Squamous Cell Carcinoma and Performance of Sentinel Lymph Node Biopsy. Int. J. Gynecol. Cancer Off. J. Int. Gynecol. Cancer Soc. 2020, 30, 583-589. [CrossRef]

13. Lei, L.; Tan, L.; Zhao, X.; Zeng, F.; Xu, D. A Prognostic Nomogram Based on Lymph Node Ratio for Postoperative Vulvar Squamous Cell Carcinoma from the Surveillance, Epidemiology, and End Results Database: A Retrospective Cohort Study. Ann. Transl. Med. 2020, 8, 1382. [CrossRef] [PubMed]

14. Xanthopoulos, E.P.; Grover, S.; Puri, P.M.; Corradetti, M.N.; Heilbroner, S.P.; Mitra, N.; Simone, C.B.; Lin, L.L. Survival Benefit of Adjuvant Radiation Therapy in Node-Positive Vulvar Cancer. Am. J. Clin. Oncol. 2018, 41, 845-850. [CrossRef] [PubMed]

15. Summary Staging Manual-2018. Available online: https://seer.cancer.gov/tools/ssm/index.html (accessed on 5 February 2022).

16. Hellman, K.; Holmberg, E.; Bjurberg, M.; Borgfeldt, C.; Dahm-Kähler, P.; Flöter Rådestad, A.; Hjerpe, E.; Högberg, T.; Marcickiewicz, J.; Rosenberg, P.; et al. Primary Treatment and Relative Survival by Stage and Age in Vulvar Squamous Cell Carcinoma: A Population-Based SweGCG Study. Gynecol. Oncol. 2020, 159, 663-671. [CrossRef]

17. Tanaka, Y.; Ueda, Y.; Kakuda, M.; Yagi, A.; Okazawa, A.; Egawa-Takata, T.; Matsuzaki, S.; Kobayashi, E.; Yoshino, K.; Fukui, K.; et al. Trends in Incidence and Long-Term Survival of Japanese Women with Vulvar Cancer: A Population-Based Analysis. Int. J. Clin. Oncol. 2019, 24, 1137-1142. [CrossRef] [PubMed]

18. Schuurman, M.S.; van den Einden, L.C.G.; Massuger, L.F.A.G.; Kiemeney, L.A.; van der Aa, M.A.; de Hullu, J.A. Trends in Incidence and Survival of Dutch Women with Vulvar Squamous Cell Carcinoma. Eur. J. Cancer Oxf. Engl. 2013, 49, 3872-3880. [CrossRef] [PubMed]

19. Meltzer-Gunnes, C.J.; Småstuen, M.C.; Kristensen, G.B.; Tropé, C.G.; Lie, A.K.; Vistad, I. Vulvar Carcinoma in Norway: A 50-Year Perspective on Trends in Incidence, Treatment and Survival. Gynecol. Oncol. 2017, 145, 543-548. [CrossRef] 
20. Rottmann, M.; Beck, T.; Burges, A.; Dannecker, C.; Kiechle, M.; Mayr, D.; Schlesinger-Raab, A.; Schubert-Fritschle, G.; Engel, J. Trends in Surgery and Outcomes of Squamous Cell Vulvar Cancer Patients over a 16-Year Period (1998-2013): A Population-Based Analysis. J. Cancer Res. Clin. Oncol. 2016, 142, 1331-1341. [CrossRef]

21. Gill, B.S.; Bernard, M.E.; Lin, J.F.; Balasubramani, G.K.; Rajagopalan, M.S.; Sukumvanich, P.; Krivak, T.C.; Olawaiye, A.B.; Kelley, J.L.; Beriwal, S. Impact of Adjuvant Chemotherapy with Radiation for Node-Positive Vulvar Cancer: A National Cancer Data Base (NCDB) Analysis. Gynecol. Oncol. 2015, 137, 365-372. [CrossRef]

22. Stecklein, S.R.; Frumovitz, M.; Klopp, A.H.; Gunther, J.R.; Eifel, P.J. Effectiveness of Definitive Radiotherapy for Squamous Cell Carcinoma of the Vulva with Gross Inguinal Lymphadenopathy. Gynecol. Oncol. 2018, 148, 474-479. [CrossRef]

23. Rao, Y.J.; Chin, R.-I.; Hui, C.; Mutch, D.G.; Powell, M.A.; Schwarz, J.K.; Grigsby, P.W.; Markovina, S. Improved Survival with Definitive Chemoradiation Compared to Definitive Radiation Alone in Squamous Cell Carcinoma of the Vulva: A Review of the National Cancer Database. Gynecol. Oncol. 2017, 146, 572-579. [CrossRef]

24. Reade, C.J.; Eiriksson, L.R.; Mackay, H. Systemic Therapy in Squamous Cell Carcinoma of the Vulva: Current Status and Future Directions. Gynecol. Oncol. 2014, 132, 780-789. [CrossRef]

25. Zapardiel, I.; Iacoponi, S.; Coronado, P.J.; Zalewski, K.; Chen, F.; Fotopoulou, C.; Dursun, P.; Kotsopoulos, I.C.; Jach, R.; Buda, A.; et al. Prognostic Factors in Patients with Vulvar Cancer: The VULCAN Study. Int. J. Gynecol. Cancer Off. J. Int. Gynecol. Cancer Soc. 2020, 30, 1285-1291. [CrossRef] [PubMed]

26. Mazzotta, M.; Pizzuti, L.; Krasniqi, E.; Di Lisa, F.S.; Cappuzzo, F.; Landi, L.; Sergi, D.; Pelle, F.; Cappelli, S.; Botti, C.; et al. Role of Chemotherapy in Vulvar Cancers: Time to Rethink Standard of Care? Cancers 2021, 13, 4061. [CrossRef] [PubMed]

27. Van de Nieuwenhof, H.P.; van Kempen, L.C.L.T.; de Hullu, J.A.; Bekkers, R.L.M.; Bulten, J.; Melchers, W.J.G.; Massuger, L.F.A.G. The Etiologic Role of HPV in Vulvar Squamous Cell Carcinoma Fine Tuned. Cancer Epidemiol. Biomark. Prev. Publ. Am. Assoc. Cancer Res. Cosponsored Am. Soc. Prev. Oncol. 2009, 18, 2061-2067. [CrossRef] [PubMed]

28. Rasmussen, C.L.; Sand, F.L.; Hoffmann Frederiksen, M.; Kaae Andersen, K.; Kjaer, S.K. Does HPV Status Influence Survival after Vulvar Cancer? Int. J. Cancer 2018, 142, 1158-1165. [CrossRef]

29. McAlpine, J.N.; Leung, S.C.Y.; Cheng, A.; Miller, D.; Talhouk, A.; Gilks, C.B.; Karnezis, A.N. Human Papillomavirus (HPV)Independent Vulvar Squamous Cell Carcinoma Has a Worse Prognosis than HPV-Associated Disease: A Retrospective Cohort Study. Histopathology 2017, 71, 238-246. [CrossRef] 